\title{
CSAE WPS/2004-27
}

\author{
Group-based Funeral Insurance in Ethiopia and Tanzania \\ Stefan Dercon ${ }^{\mathrm{a}}$, Tessa Bold ${ }^{\mathrm{a}}$, Joachim De Weerdt ${ }^{\mathrm{b}}$ and Alula Pankhurst ${ }^{\mathrm{c}}$ \\ ${ }^{a}$ University of Oxford, United Kingdom \\ ${ }^{\mathrm{b}}$ Research Director, Economic Development Initiatives, Tanzania and C. University of Leuven, Belgium \\ ${ }^{\mathrm{c}}$ Department of Sociology and Social Anthropology, Addis Ababa University, Ethiopia.
}

September 2004

\begin{abstract}
A funeral is a costly occasion. This paper studies indigenous insurance institutions developed to cope with the high costs of funerals, based on evidence from rural areas in Tanzania and Ethiopia. These institutions are based on well-defined rules and regulations, often offering premium-based insurance for funeral expenses. Increasingly, they are also offering other forms of insurance and credit to cope with hardship. The paper argues that the characteristics and inclusiveness of these institutions make them well-placed as models to broaden insurance provision and other developmental activities in these communities. The history of these institutions is characterised by a resistance to attempts of political capture, and helps to understand their apparent resistance to engage more broadly with NGOs and government agencies. As a result, any attempt to expand their activities will have to be done cautiously.
\end{abstract}

Keywords: Risk-Sharing, Insurance, Africa, Ethiopia, Tanzania JEL codes: 017, G22, Z13

Acknowledgements

Corresponding author: stefan.dercon@economics.ox.ac.uk. The authors would like to thank Johannes Jütting, Ulrich Hiemenz and seminar participants at the World Bank for useful comments. All errors are our own. This paper builds on work initially financed by the OECD Development Centre, Paris. 


\section{Introduction}

This paper focuses on a prevalent but largely unstudied institution in developing countries: indigenous associations for the provision of funeral insurance. In Ethiopia and Tanzania, they have in recent decades evolved to into well-structured organizations, often offering insurance beyond funerals. This paper discusses their history, functioning, the extent of insurance offered and the scope for building on these institutions to broaden insurance, based on a survey in rural Tanzania and Ethiopia. It assesses whether they could be 'scaled up' via interventions by NGOs or the state, to offer insurance against other risks. It provides some evidence of the extent to which developmental activities are successfully being provided via these institutions. It concludes with a number of conclusions for policy.

Many studies have documented the extent of risk experienced and the responses to risk in developing countries (for reviews, see Morduch (1995), Townsend (1995) and Dercon (2002)). One key response is that households try to reduce the consequences of the risk in their income by a variety of risk coping mechanisms, including engaging in forms of risk-sharing via informal arrangements. The economic literature on risk-sharing arrangements, including key empirical papers (such as Townsend (1994), Grimard (1997), Ligon et al. (2002)) as well as theoretical papers (including Coate and Ravallion (1993), Genicot and Ray (2003)) have in common that they effectively focus on 'informal' risk-sharing arrangements, to be understood not only in the sense that they were taking place outside the market place but also that they were 'informal' in that they were not based on well-defined 'formal' associations, with formally defined, written sets of rules or regulations governing their operation. These institutions are sustained over time on the basis of 
implicit rules enforced by social norms; so that once joined no-one is tempted to defect later when they realize that their own contribution is outweighing their personal and social benefits. However, much recent theoretical literature has shown that norms or other rule-based enforcement mechanisms are not necessary for these arrangements to be sustained. In other words, incentive systems within the arrangements can be designed to make the contracts ex-post self-enforcing.

Empirical investigations on risk-sharing arrangements have largely focused on 'informal' arrangements between households and individuals based on concepts such as the extended family, neighbors or village-wide networks, but not on well-defined networks or associations formed with a specific focus on insurance. There is some work that considers linkages between individuals and households that identify specific people as their insurance partners (Fafchamps and Lund (2003), Ayalew (2003), Dercon and De Weerdt (2002)). Even so, these contributions do not focus on groups or associations - but largely on bilateral arrangements with a risk-pooling purpose.

This paper goes beyond this analysis by discussing insurance groups, indigenous associations common in developing countries with a specific focus on insurance and with well-defined rules and obligations, in the form of membership rules, specific contributions and fines related to deviant behavior. In particular, it discusses funeral societies in Ethiopia and Tanzania, based on a unique data set on the functioning of these groups, with matching household level data on the members.

It has to be acknowledged that there is a large literature on groups and associations in developing countries and their economic impact. However, most of its focus is on their role as 'social 
capital'. ${ }^{1}$ The purpose or functioning of these groups is less relevant in this literature. Another literature focuses on development initiatives using community-based organizations. One strand is related to health insurance, since in recent decades many initiatives have developed around voluntary but community-based health insurance (CBHI) schemes (Jütting (2003), Atim (1998)). Although some of the issues involved are comparable to those related to indigenous insurance groups, a key difference is that CBHI schemes typically develop with clear linkages to NGOs or specific health facilities. ${ }^{2}$

There is at present only a limited discussion of funeral associations in the literature. In the Ethiopian context, Dejene $(1993,1998)$ has discussed these organizations in some detail from an economic point of view. This study is different in that it is directly based on survey data on the functioning and membership of these institutions in a rural setting. There is a limited sociological and anthropological literature on these institutions as well (for example, Pankhurst (2003)). In the Tanzanian context, there appears to be no analysis of these institutions. More generally, Rutherford (2001) has documented the existence of insurance mechanisms for funerals across the developing world. Still, no systematic economic analysis of these institutions can be found in the literature. Although the present analysis is largely economic, it is also informed by anthropological work, focusing on the historical context and evolution of the particular format of the institutions.

${ }^{1}$ Using Putnam et al. (1993), social capital can be defined as referring to features of social organisation, such as trust, norms and networks that can improve the efficiency of society. In particular, the focus is on the external effects of community relations on outcomes of interpersonal interactions: 'strong' social capital tends then to be associated with economic success.

${ }^{2}$ A more detailed discussion of CBHI schemes in relation to funeral associations is in Dercon et al. (2004). 
A number of stylized facts make the study of funeral insurance in developing countries even more important. First, funeral expenditure in much of the developing world is usually large and tends to be a large proportion of households' monthly income. Roth (1999) suggests that the poor in South Africa will spend approximately 15 times their average monthly income on funerals. Our own surveys also suggest substantial figures for Ethiopia and Tanzania. Rutherford (2001) finds that funeral insurance is one of the most popular products offered by more formalized microfinance institutions. Secondly, it is also a highly insurable event in these settings. Moral hazard is unlikely to be relevant for insuring a funeral. Given relatively high mortality, it is a common event in families, but still typically with relatively low covariance.

The next section presents the basic characteristics of these groups based on unique survey data on these groups in both countries, including the insurance cover provided and the functioning of the groups. A brief history of these groups is discussed in section 3. Section 4 briefly tackles the economic rationale of the observed functioning, suggesting that they may well provide a successful recipe combining the advantages of 'informal' insurance relationships, championed in the informal risk-sharing literature, with workable solutions for stability and sustainability as an institution providing effective cover against a number of risks, most notably funeral risk. Section 5 discusses an analysis of the characteristics of members of these groups and the issue of who is a member of these groups. A key finding is that these groups appear remarkably inclusive and that, contrary to informal arrangements of mutual support, different socio-economic groups tend to be members of the same groups. In any case, in both contexts there are relatively substantial groups that appear to be well-organized and structured, with clearly defined rules and regulations, and experienced in handling financial and organizational matters. This may make them suitable for 
other developmental activities, and possibly for scaling them up in terms of activities. Section 6 discusses the possibility of scaling up. Section 7 concludes.

\section{Characteristics of the Funeral Associations}

The study draws on data from two rural contexts. First, there are data from a number of communities in rural Ethiopia, studied as part of the Ethiopian Rural Household Survey. This survey has been collecting panel data on households and communities since 1989 , focusing on 15 communities from across the country ${ }^{3}$. In this study, the data are used from a sub-sample of these funeral societies in these villages for which key figures could be interviewed in the village. In total, detailed data has been collected on 78 funeral societies in seven villages ${ }^{4}-$ about half the number of funeral societies present in these villages. In one village, the data were matched to the households in the household survey, allowing some more detailed analysis. The village in question consists of the communities in Sirbana Godeti, a relatively prosperous village in Oromiya Region in central Ethiopia, where about 30 funeral groups were identified, about half of which were studied. Additional data, from communities in Southern Ethiopia, complement this analysis, although for the time being these data are not fully analyzed ${ }^{5}$. It should be stressed that some of the detail of the way the organizations function is different across rural and urban Ethiopia, but most of the fundamental characteristics are common across large parts of the country.

\footnotetext{
${ }^{3}$ Details of the overall survey are in Dercon and Krishnan (2003).

4 'Village' is used to mean a Peasant Association. Rural Ethiopia is administratively divided in Peasant Associations, which are a collection of communities.

${ }^{5}$ The data on Sirbana Godeti were collected in 2002, but the data on the other villages were only collected in October to December 2003, and are not yet matched to the household data.
} 
We also have data from a village in Kagera Region in Western Tanzania, called Nyakatoke, relatively close to the Ugandan border, near Lake Victoria. A detailed survey of all community organizations and informal networks, with an emphasis on insurance-based linkages, was conducted - details are in De Weerdt (2004). A total of 20 groups with a prime insurance function were identified and were included in the analysis.

In Ethiopia, the funeral associations are known as the iddir (e'dir) - associations that ensure a payout in cash and in kind at the time of a funeral for a deceased member of the family of a member of the group ${ }^{6}$. In the Tanzanian village, the associations studied are providing additional insurance beyond the basic 'traditional' funeral society, the Bujuni. They include seven Women's Associations, themselves united in the Muungano (the Union of Women's Groups), four neighborhood and five religion based groups. As will be argued below, their main function is insurance, and funeral insurance is the key and unifying element. Table 1 summarizes a number of the common elements across contexts - they apply to all the groups studied in this paper.

\footnotetext{
6 'Iddir' is the generic name. In some areas, other local names are used - such as 'kire' in parts of Wollo. They are all referred to as iddir in this paper.
} 
Table 1 Common elements in funeral groups in Tanzania and Ethiopia

Membership

Founding members plus by application; payment of a membership fee; some groups particular membership restrictions (women, religion).

Insurance schedule

If funeral, payment schedule conditional on relationship of deceased to member.

Form of Payout

In cash plus in kind (food plus use of capital goods) plus labor.

Rules and regulations

Written rules, and book-keeping. Fines for non- or late payment or no show (in the case of labor contributions).

Governance structure

Elected Committee.

Spread

Large number of groups per community, with individuals that are members of several groups.

Source: data collected by the authors.

Membership is clearly defined, with written lists, and by no means do these groups consist of a loose, rapidly changing association of people. Membership is confined to founding members and those applying to become members afterwards. In both contexts there is a membership fee to be paid when joining after formation. A number of instances were found where groups have particular restrictions, such as by gender or age. Payments are made when members incur costs related to funerals (and, as will be discussed further, in some cases related to other instances as well), related to the death of a well-defined set of relatives. The actual payout is conditional on the relationship of the member to the deceased: for example, the payment for the spouse of a member is typically different from the payout for a child or for uncles and aunts.

Payouts occur in cash and in kind (food) as well as in the form of labor services. In both contexts, there are written statutes, bylaws and records of contributions and payouts. The rules define 
membership procedures, payout schedules, contributions and also a set of fines and other measures for non-payment of contributions, or for matters such as not showing up at funerals or not contributing enough in terms of labor on these occasions. Finally, one of the most remarkably findings of the work in these communities was the very large number of groups with a focus on funeral insurance in these communities. In Sirbana Godeti in Ethiopia, a community about 400 households, about 30 groups were found. In some other villages in Ethiopia, a somewhat more modest number seems to be present but still five or more; but in a number of villages the number of iddirs was well above 50 and more - in Imdibir, one of the study villages, the study is able to identify about 80 to 100 groups, albeit not all just covering the village, but with substantial membership in the village, despite having only a population of about 350 households. In Tanzania, the village studied (Nyakatoke), had a population of 120 households only, but 20 groups were identified. It is obvious from this that people can and usually are members of more than one association for funeral insurance - see below more on this.

What is the insurance provided by these groups? All groups in Ethiopia give funeral insurance; all but one group identified in Tanzania provided funeral insurance (the exception being a small group of 18 , with only two members from the specific village). Table 2 gives the benefits paid out by the funeral society when the member dies. At the relevant exchange rates, the payout in both countries is approximately $\$ 20$ on average per group. Note that the figure for Tanzania includes in-kind benefits (in terms of food) of approximately of 80 percent of this figure. For Ethiopia, these figures do not include the in-kind benefits, although they are typically more limited: in about a quarter of cases, some in-kind benefits were reported in Ethiopia, but relatively modest in value 
(usually coffee and injera, the basic staple food made from teff). ${ }^{7}$ In Tanzania, all groups reported in-kind contributions, in all but one case much more substantial than the cash contributions. These calculations do not include some labor services provided in a minority of cases in both countries. In Tanzania, the seven Women's groups ask members to help at the funeral typically for one day, but this is not done by any of the other groups; in Ethiopia, about half the groups contribute labor (beyond the funeral) as well - typically one to three days of labor per member, including farm and related work. Especially in Ethiopia, this contribution is rather substantial.

Table $2 \quad$ Payouts in case of funeral of a member

\begin{tabular}{lccc}
\hline & Benefit & Standard deviation & Median \\
\hline Tanzania (in TSh) & 16655 & 16477 & 13000 \\
Ethiopia (in Birr) & 206 & 177 & 150 \\
\hline Source: Own data. Tanzania includes 13598 TSh in-kind benefits. Ethiopia does not include in-kind benefits. Exchange rates at the time of the
\end{tabular}
surveys: $\$ 1=10$ birr and 800 Tanzanian Shilling.

But there are a number of other crucial differences, summarized in table 3 below. In Tanzania, the groups identified only expect the members to provide a cash contribution to the member experiencing a death when the funeral actually takes place. In Ethiopia, about 80 percent of the groups were charging a regular contribution, usually monthly, from the members. ${ }^{8}$ In the village studied in more detail, all but one funeral society operated on this principle. In more urbanized contexts other studies found that this percentage is close to one hundred percent (Pankhurst, 2003).

\footnotetext{
${ }^{7}$ This may be different in other areas of Ethiopia, not surveyed. Mariam (2004) reports on iddirs in Southwestern Ethiopia only providing in kind benefits to their members in terms of food, materials and labour in the case of a funeral.
}

${ }^{8}$ Most of these groups would also ask for a fixed additional contribution at the time of a funeral. 
A key consequence of this phenomenon is that some of these groups retain very substantial savings. In fact, in the full sample (i.e. including those not charging a fixed regular contribution), asset holdings were on average about 1900 birr (\$190), a substantial sum in a country with a yearly GDP per capita of only about $\$ 100$. Many iddirs were found to have much more in terms of accumulated savings; the highest sum reported was about \$3000. Obviously, regular membership contributions and group sizes play a role here as well. Average contributions per month per member of the 63 Ethiopian groups charging a regular contribution (either weekly, fortnightly or monthly) were 1.64 birr per month (the median is 1 , the range was 0.25 to 5 birr). Contributions are fixed per member, irrespective of age or family size. Groups in Ethiopia were also charging substantial entrance fees for anyone currently wanting to join: about 42 birr, or 25 times the monthly contribution. Interestingly, about 40 percent of reported groups to set these entrance fees as a fixed contribution, the rest suggested a formula based on the current assets and property per member. Furthermore, groups in Ethiopia were larger, on average about 84 members, with a median of 55, compared to an average size of 24 (median 18) in Tanzania. ${ }^{9}$ Although a few very small iddirs were found in Ethiopia, in each of the seven villages the average size is larger than in Tanzania.

There is also a striking difference in the structure of the Ethiopian funeral societies relative to the Tanzanian insurance groups. In Tanzania, they are clearly providing supplementary insurance over and above the village level burial society, the Bujuni (which is the Haya word for 'mutual help'). The Women's groups explicitly state this in their constitution: only women from Nyakatoke whose husband is a member of the village burial society. The insurance they offer is

\footnotetext{
${ }^{9}$ Mariam (2004) reports even a mean group size of 175 in his sample of 52 iddirs.
} 
meant to cover expenses not covered by the burial society. The neighborhood and religion-based groups are similarly providing supplementary cover. The Women's groups have further structure: there are seven groups, all united in Muungano, the Union of Women's Groups. The Muungano offers a standard cover in terms of insurance, and then each group offers additional benefits, slightly different between groups. For example, Bertha's group has 11 members and offers TSh 100, 30 fingers of bananas and 3 bowls of beans when there is a funeral, while Eles' group has 17 members and offers $3 \mathrm{~kg}$ of meat, 2 hands of bananas and 5 bowls of beans ${ }^{10}$. Neighborhood or religious groups similarly offer particular benefits, such as labor before the funeral, which can cater for specific needs for particular households. Clearly, there is an element of 'choice' of product in these communities and people can express their preferences for different insurance packages.

The Ethiopian groups are relatively speaking more homogenous in terms of products and typically do not have any 'super-structure', in terms of conditional membership. Households join one or more iddirs, with a large number present in many communities, each offering more or less similar products, largely differentiated in terms of the amount of cash offered in times of a funeral and, related to this, the regular contribution paid.

${ }^{10}$ Groups that have no name are identified by the name of the chairperson. 
Table 3

Differences between Ethiopia and Tanzania

\begin{tabular}{|c|c|}
\hline Ethiopia & Tanzania \\
\hline Usually, regular contributions in cash (average about $€ 0.16$ ) & Contribution only when the funeral takes place \\
\hline Cumulative Asset Holding, largely in cash (mean=€190). & Limited assets (durables) \\
\hline $\begin{array}{l}\text { Usually relatively substantial entrance fee (mean=€4 per } \\
\text { family). }\end{array}$ & Relatively limited entrance fee (mean for women's groups $=€ 1$ ) \\
\hline Mean group size is 84 (median=55) & Mean group size is 24 (median=18) \\
\hline $\begin{array}{l}\text { No interlinked groups } \\
- \text { no restrictions on payouts. }\end{array}$ & Women's group is conditional on membership of Bujuni. \\
\hline $\begin{array}{l}\text { Groups with remarkably similar organizational structure, but } \\
\text { contributions and cash-payouts different across groups }\end{array}$ & $\begin{array}{l}\text { Product differentiation in terms of insurance offered in terms of } \\
\text { cash, labor and goods. }\end{array}$ \\
\hline $\begin{array}{l}\text { Overall focus is funeral insurance, but also credit and some } \\
\text { additional coverage. }\end{array}$ & $\begin{array}{l}\text { Focus is on funeral and, for women's groups, hospitalization } \\
\text { insurance. }\end{array}$ \\
\hline
\end{tabular}

Source: data collected by the authors.

In both countries, funeral insurance is the key service offered by these associations, and the prime motive for most to join them. Still, some alternative products are being offered by these groups. In Tanzania, 13 out of the 20 organizations also offer hospitalization insurance: a fixed payout usually in term of cash and sometimes some labor whenever the member or close family is admitted to hospital and a relative has to stay with the person. The average payout is about $€ 4$ per instance, well below payouts in case of funeral (only about 15 percent of funeral payouts), but still significant.

The groups spoken to in Ethiopia also clearly emphasize funeral insurance, but a substantial number offer other benefits to their members. First, about 64 percent of groups offer loans to members, provided the funds are available, with clear (and strictly enforced) rules governing repayment. Members have to present a case for obtaining a short-term loan, and the most 
commonly accepted reasons are additional funeral spending, illness and destruction of a house to put it differently, short-term credit is offered to provide additional cover, mainly for shocks. Secondly, 64 percent (but not necessarily the same groups as those offering loans), offer other forms of insurance, but the cover offered is clearly dependent on the group. Table 4 summarizes the types of insurance they offer and it is clear that each group that provides additional cover offers typically only a limited set of other benefits, such as fire and house destruction insurance. About 30 percent of the groups offering additional cover provide payouts in case of serious illness in one way or another. Note that in all cases, no additional separate premium is charged, but all is included in the basic premium. ${ }^{11}$

Table 4 Types of additional of insurance offered in Ethiopia

(percentage of those groups offering additional cover)

\begin{tabular}{ll}
\hline Destruction of House & $40 \%$ \\
Illness & $30 \%$ \\
Fire & $28 \%$ \\
Death of Cattle & $24 \%$ \\
Harvest & $14 \%$ \\
Wedding & $14 \%$ \\
\hline Source: data collected by the authors. &
\end{tabular}

\section{History of the Funeral Associations}

Most economic research has tended to view informal arrangements as 'traditional' responses in the context of limited market penetration. In many ways, the funeral associations are neither informal nor traditional. The emergence of these particular institutions is a relatively recent development. In Ethiopia, they are likely to have evolved from migrant support organizations,

${ }^{11}$ In a study by Mariam (2003) of 52 iddirs in mainly rural Ethiopia, similar results were found. He reported that besides funeral expenses, insurance and/or credit was also given for house fire (44 percent) and illness episodes (20 percent). 
possibly as late as the beginning of the $20^{\text {th }}$ century, and they started spreading rapidly after the Italian occupation. In Tanzania, they evolved as defiantly independent institutions after a period of attempted capture by the state during the Nyerere presidency in the $1980 \mathrm{~s}$. In both cases, their recent history suggests a consistent reformulation in response to changes in market penetration and in the political context. These institutions are best understood as organizational structures developed in interaction with the general socio-economic and political context, and that they evolved in response to changes in this environment ${ }^{12}$. They are not 'informal' - the detailed rules and regulations, and indeed the links with local court systems would suggest otherwise. Nevertheless, it is appropriate to refer to them as non-market institutions, since they are not using market processes to provide insurance, even if the contracts offered to members closely resemble those typically offered in insurance markets.

Their complex relationship with the state deserves some more attention. In Ethiopia, until the 1960s, iddirs had been relative invisible institutions. This changed when, in the 1960s, municipal authorities in Addis Ababa and more generally the Ministry of National Community Development sought to promote collaboration between iddirs and the government. At the same time, some politicians used these associations as platforms for political purposes. In this period, different iddirs became involved in broader development activities. An attempted coup in 1966, partly blamed on an indigenous migrant association, meant that the state tried to establish more control over these associations, including iddirs. The revolution of 1974 brought the Derg to power, after which the leadership of the iddir were considered reactionary elites and most iddirs retreated to

${ }^{12}$ This does not contradict the earlier point that the institutions can be seen as responses to market failure. Effectively, they are non-market institutions taking on functions that a perfectly working insurance market could perform. But the specific form these institutions take on is still conditioned by the local context. 
focus only on burial activities, and the formerly strong urban associations were marginalized. Still, the spread throughout rural Ethiopia clearly continued, while the size of some urban based iddirs increased considerably ${ }^{13}$. In recent years, the current government has increased its interest in working with associations like the iddir, but at the same time insisting on registration and considering them as vehicles for policy implementation. In the same period, certain NGOs, notably ACORD, have started to work with iddirs, although this remains largely a limited number of instances or activities. One response appears to have been that some iddirs have themselves also started to try to expand their activities. For example, 21 iddirs in the west of Addis Ababa have formed an umbrella association, strictly politically neutral but focusing on developmental activities.

The experience in Nyakotoke in Tanzania provides another interesting example of how these institutions evolve in response to changing political contexts. The village burial society, the Bujuni (meaning 'mutual help' in Haya) is a relatively old indigenous institution. However, it only became more formalized after 1973, under impulse of a migrant from another village, who had suggested making the rules and regulations more explicit. Some form of mutual cooperation existed similarly among women, but formalization came much later. In 1973, as part of the radical changes instigated by President Nyerere's ruling party, women were forced to 'unite' in formal groups as part of the UWT (the Swahili acronym for the Union of Tanzanian Women), organized in relatively large 'village' level groups interpreted to include many communities beyond Nyakatoke, with pressure to set up village shops and other collective institutions via (forced)

${ }^{13}$ There are examples of large professional or work-based iddirs in urban areas. Note that the spread in urban areas is sufficiently large to imply that the vast majority of urban dwellers will be members of one or more iddirs, across social classes. Indeed, even the World Bank's country office has its own iddir. 
contributions. The village shop became bankrupt five years later and increasingly the UWT groups became just political institutions. However, after this experience, some 70 women decided to set up a group involved in economic activities to raise money for events such as funerals, births and hospitalization, independently of the UWT and surviving its gradual disappearance. The group did not survive long and from 1984 factions broke away, and effectively these groups became the predecessors of the current groups, with a common element of providing insurance for funerals and hospitalization. In 1994, the different women's groups (under impulse of a recent migrant) formed the Muungano, the union of the women's group, integrating the basic minimum funeral and hospitalization insurance. Since then, the different groups have experienced a relative degree of stability via the Muungano. Overall, the groups clearly conform to the idea of an indigenous association, even thought they were initially inspired by the formalized activities of the UWT. There is no evidence of any outside involvement in any of the current groups or their predecessors, and linked to the bad experiences in the UWT, they have stayed clear of any political capture even at the local level, steering away from the activities of the ruling party or the emerging opposition. The rules and regulations have clearly evolved over time, moving gradually further away from economic activities towards a clear focus on specific insurance.

\section{The Economics of Funeral Associations}

Why do these associations take the form observed in both countries? This section discusses some of the key economic issues that these associations appear to resolve, as well as provide some suggestions on why these organizations function in the way observed. Much of this work is preliminary and indeed much more applied theoretical work is required to properly understand 
these groups. Bold (2003) and Bold and Dercon (2004) provide more details on these issues and present some theoretical models that may account for some of the characteristics of these groups.

First, a few relatively obvious points can be made. Insurance provision in any form is affected by asymmetric information issues, leading to the problems of moral hazard and adverse selection, as well as by enforcement problems, if contract enforcement is not possible by straightforward legal means. Covariate risk is also problematic. While formal insurance markets may not have developed in rural Ethiopia and Tanzania for exactly these reasons, informal arrangements within well-defined communities may face a better informational environment (i.e. monitoring is less costly) and they may be able to use local means for enforcing contracts (from indigenous customary law to socially enforceable norms).

However, it is striking that despite this context, insurance takes a much more formal structure (with written rules, obligations and punishments) suggesting that purely 'implicit' contracts are less desirable. Indeed the actual insurance and contracts offered by the groups suggests that issues of information and enforceability are relevant and in need of some form of second-best solution. For example, the risks insured are clearly chosen so as to avoid moral hazard - with funeral insurance the most dominant form. While the loss of earnings and wealth linked to other shocks, such as destruction of house, fire, illness and death of cattle are high, these shocks are less prevalent (table 4). Similarly, despite the high information environment, the payouts, for example, for hospitalization in Tanzania are defined in the form of a lump-sum with the requirement for proof of hospitalization, and a clear deductible, in that costs incurred are only partially covered. In short, the contracts take forms closely resembling common 'insurance' contracts even in these non-market contexts. Similarly, the iddir constitutions clearly stipulate, first, that no collateral is 
required but instead a guarantor, which is a member of the group responsible for the repayment. Furthermore, they typically state that if necessary the local (village) courts will be used to sue the guarantor in case of non-repayment ${ }^{14}$. In other words, the result does not appear to be a perfect risk-sharing environment, but contracts probably constrained by information and enforcement problems, reflected in extensive rules and regulations.

At the same time, it is striking that the move towards more formal contracts does not mean that risk-pooling at a really large scale is being achieved, for example across many villages and more in the form of 'anonymous' market-like relationships. This does not appear to be the nature of the groups. In Tanzania, all but one group considered are exclusive to residents of the particular village studied. In Ethiopia, the membership of most of the iddirs similarly is based on local communities. The relatively small size, the relatively localized nature of groups and the type and form of cover offered suggests that enforcement and information problems are indeed substantial problems.

What are the advantages of forming groups rather than relying on voluntary 'reciprocal' transfers? It is important to note that forming a group with written rules is not the same as ensuring that the arrangement will always be enforceable afterwards. To put it differently, standard theoretical explanations suggest that 'informal' arrangements could be self-enforcing, through repeated interaction, provided participation constraints - the incentives for particular individuals to stay in the arrangement in each ex-post outcome - are properly taken into account, even though these contracts are typically only 'second-best' risk-sharing contracts (Coate and Ravallion, 1993;

${ }^{14}$ These village courts are called 'kebele courts' and are part of the formal legal system in Ethiopia. 
Ligon et al., 2002). Group-based systems are definitely not immune from the problem that individuals may have incentives to leave the arrangements, which may affect the continuation of the schemes. Even though groups have been known to litigate against particular members in Ethiopia, this is done regarding repayment of loans, not related to issues of individuals wanting to leave the arrangement. In fact, in both countries, anyone is free to leave the group. As a consequence, the issue of sustainability is relevant for groups as well, and a priori there is no reason to suggest that it is less relevant.

However, the best way to understand membership fees and the large number of cases in Ethiopia where regular contributions are collected is that they act as a commitment device. In fact, from the point of view of pure insurance or risk-sharing, there is no a priori reason to charge members a fee, definitely not a fee related to the current assets of the group: the history of events and payouts is not relevant for the future distribution of payouts across the members, so no charge should be made for late-entry. However, by charging entrance fees, the surplus available if one faces a negative shock will be higher, or the risk that one will be required to pay extra when someone else faces a negative shock will be lower; in short, the expected benefits from being in the group increase, increasing the incentives to stay in once entered into the arrangement. Ex-ante payments, before the distribution of shocks is known, similarly increase the incentives to stay in the group ex-post.

These issues become even more relevant when addressing the issue of the stability of the entire group involved in risk-sharing activities, beyond just individual incentives to deviate. Genicot and Ray (2003) have suggested that pure 'informal' groups of mutual support, that are stable to subgroups breaking away and setting up their own informal arrangement, may well only be very 
small. The possibility of group-savings appears to reduce these incentives to break away (since the assets cannot be retrieved when leaving the group), and possibly leading to larger stable groups (Bold (2003)). Entrance fees similarly reduce these incentives. As mentioned above, the groups are relatively larger in Ethiopia than in Tanzania. The fact that entrance fees and especially average asset holdings are substantially larger in Ethiopia may well be part of the explanation for larger sustainable groups. Also, when looking at the average age of the existing groups, in Tanzania it was only about 5 years while in Ethiopia the average was fifteen years. But, in both cases, the incentives to break away remain, apparently limiting group size well below village size.

\section{Exclusion, Coverage and Impact}

These insurance groups are remarkable not just by their functioning; their membership is also widespread. In this section, it is studied what determines membership, how much protection is offered and how important this insurance is for its members. In the sample of 15 Ethiopian villages (the ERHS), it was found that at about 80 percent of households were members of at least one iddir. However, when excluding two villages in the most Northern region of Tigray, where, apparently, these institutions are not yet present, membership is virtually comprehensive: they could be found in all the other villages included in the sample, and in almost all villages, more than 95 percent of households were members of at least one group. ${ }^{15}$ In one village, Sirbana Godeti, where groups were matched with household data, it was found that households were

${ }^{15}$ Other surveys confirm the widespread membership. Open-ended questioning on which social organisations households are members of in a sample in South Wollo collected found about 80 percent of households to be members of at least one iddir (Mogues (2004)). Mariam (2003) reported in his survey of about 1200 households in 40 largely rural communities in Ethiopia that 87 percent of households were members of an iddir. 
members of up to 8 groups, and on average a member of between two and three groups. In Tanzania, with data only on one village, about 95 percent of the households were member of the village level Bujuni. Almost all households with a female adult took out additional insurance from one of the seven village women's groups. Overall, households are a member of about three groups.

The widespread membership across the population suggests that these groups are quite inclusive. Even though the percentage of people not included is relatively small, it is still relevant to explore who may not be included in these schemes. Using the Ethiopian data ${ }^{16}$, it was investigated whether membership was affected by socio-economic characteristics. It was found that the probability of membership increased with the age of the head and with household size. This is consistent with people typically only considering joining iddirs after they marry and start a family. There was no effect from current living standards. ${ }^{17}$ Mariam (2003) suggested that in his sample of 1200 households, mainly in rural Ethiopia, those not members were typically either newly arrived migrants, that had not yet been well established in the area, or those not yet married but already cultivating their own land as an independent family member. In Tanzania, the few not included in any scheme were not significantly different from others. In both contexts, funeral groups were originally based on ethnicity, religion and kinship, but the large number of different

\footnotetext{
${ }^{16}$ This analysis uses the $4^{\text {th }}$ round of the data (from 1997) which included specific questions on membership. Membership in that round of the data was about 75 percent - below the estimate from other rounds - possibly due to slight underestimation related to less precise use of the local terms to describe the funeral societies, affecting data collection in two villages (one in Northern Shoa and one in Daramolo). The regressions used a probit model, using community level fixed effects.

17 In particular, current consumption levels are not significant. Land holdings are also not significant, while there is a very small effect from livestock holdings, increasing the probability of being a member, but the marginal effect is very small and only significant at 11 percent.
} 
groups available means that there everyone could in principle be a member of some group. For Ethiopia, Mariam (2003) added that all iddirs in his sample area now state that anyone in the same locality, regardless of religion or socio-economic status could apply to be members. In Tanzania, qualitative interviews with members and non-members confirmed that once one is willing to adhere to the rules of the group and give timely contributions when the rules so demand, there is likely to be no objection to anyone joining a group.

However, in both cases there is evidence that the extent of coverage is higher for richer households. In both contexts, households can be members of different groups. As a result, people can choose to have more insurance coverage by joining more groups, or by joining groups offering higher insurance linked to higher contributions. This is investigated further in both data sets. In the data on Nyakatoke, an investigation on the coverage taken out by households suggested that the mean funeral coverage was equivalent to about 21 percent of total yearly household consumption (while health coverage offered was on average about 2 percent). In Ethiopia, it was not possible to analyze coverage on the full data set, but there is data on total payments over a four month period in 1997 by households to iddirs, which will give a good indication of the coverage they could themselves receive. Table 5 reports the result of simple regression analysis, linking the funeral coverage (Tanzania) or total contributions (Ethiopia) to a set of characteristics. For the Tanzanian data, ordinary least squares were used; for Ethiopia, where about a fifth of households did not spend on iddirs, a tobit model was used. In Ethiopia, the regression controls for community fixed effects, so the focus is on within-village differences. The characteristics used were household size, age of the household head, whether the head had completed primary school, sex of the head and a set of (cumulative) dummies for wealth (based 
on the overall consumption levels). The Tanzanian data also allow for controls for the location within the village and for the shared genetic stock with other people in the village.

Table 5 Determinants of funeral coverage/contributions per household

\begin{tabular}{|c|c|c|c|c|}
\hline & \multicolumn{2}{|c|}{$\begin{array}{c}\text { Tanzania } \\
\begin{array}{c}\text { Total funeral coverage per household } \\
\text { (ordinary least squares) }\end{array}\end{array}$} & \multicolumn{2}{|c|}{$\begin{array}{c}\text { Ethiopia } \\
\text { Total contributions per household } \\
\text { (tobit model with community fixed effects) }\end{array}$} \\
\hline & Coefficient & p-value & Coefficient & $\mathrm{p}$-value \\
\hline Household size & 4601.6 & 0.026 & 1.452 & 0.000 \\
\hline Age of household head & 272.1 & 0.471 & -0.046 & 0.193 \\
\hline Primary school completed? & -1937.0 & 0.875 & -2.794 & 0.113 \\
\hline Sex of head & -1265.9 & 0.933 & 2.811 & 0.027 \\
\hline Genetic share*1000 & 1065.2 & 0.087 & - & - \\
\hline Distance to centre of village & 6.5 & 0.863 & - & - \\
\hline Richest 75 percent (dummy) & 32741.2 & 0.040 & 2.568 & 0.092 \\
\hline Richest 50 percent (dummy) & -17264.6 & 0.275 & 2.308 & 0.109 \\
\hline Richest 25 percent (dummy) & 7208.1 & 0.634 & 3.055 & 0.039 \\
\hline Constant & 62.1291 & 0.058 & -24.602 & 0.000 \\
\hline R-squared & \multicolumn{2}{|c|}{0.135 (adjusted) } & \multicolumn{2}{|c|}{0.0654 (pseudo) } \\
\hline
\end{tabular}

The regression suggests that larger households take out more coverage, which suggests they respond to the incentives given in the scheme: larger households stand to benefit more in the system. In all groups the policy covers all members of the household irrespective of total household size. However, there is no extra cost when insuring extra individuals within a household - so it is relatively more advantageous for larger households to join. The other key effect is that the poorer households have significantly less insurance. In the Tanzanian data, the richest 75 percent dummy is positive and significant, while no other wealth dummies are significant. The size of the wealth effect suggests that in Tanzania, the poorer have typically 25 percent less coverage than the average household. Similarly, in Ethiopia, contributions systematically increase in wealth, and there is clear evidence of the richest 25 percent insuring themselves significantly more than the rest. ${ }^{18}$

${ }^{18}$ It is standard practice to have multiple memberships of groups as a means of increasing coverage. Alternatively, it could be asked why they are not choosing to increase contributions in the existing groups to get more coverage. When discussing this with the groups, it was argued that 
A further issue is the composition of the groups: who joins what type of group? Is there any evidence of matching or selection in the group composition? Assortative matching is typically considered as a benefit in terms of being able to save on information and enforcement costs - it is often suggested that similar people will find it easier to monitor and enforce contracts (Hoff (1997), Ghatak (1999)). Nevertheless, analysis of the group composition in the matched data of households and groups in both countries found only limited evidence of matching. For example, there is no evidence that richer people joined specifically particular groups. In De Weerdt (2004), this was found rather different when investigating pure 'informal' linkages between households in the Tanzanian sample (where linkages were defined on the basis of household and individual level questions on "who would you turn to for help?" and "who would you give assistance?"). The evidence showed that wealth and geographical distance mattered significantly and strongly in determining these linkages. In other words, this suggests that these more formal organizations can afford to allow people from a more diverse background to become members, presumably since clear rules and regulations can compensate for some of the informational and enforcement advantages of social and geographical proximity.

Finally, how important is this funeral protection for the households involved? Funeral costs are very substantial - although the full costs are hard to estimate, but definitely a significant proportion of a months' income. In Ethiopia, the average cash payout per iddir is about 40 percent

the only feasible group structure is one in which everybody contributes the same, so that coverage is identical among members. Furthermore, it was often hard to find consensus among all members to increase contributions once a group is established so that for a member to obtain higher coverage, the most feasible route would be to also join another group, unless enough people can be found willing to set up a new group with higher coverage, and leave the original group. As discussed before, membership fees limit the incentives for this behaviour. 
of monthly household consumption (and the average household is usually members of more than one group), so iddirs are crucial to allow households to cover these expenses. In fact, the Ethiopian Rural Household Survey data suggest that for the poorest wealth quartile, monthly payments to the iddir are about 40 percent of total monthly health expenditures - and for the richest groups still about 30 percent $^{19}$. In Tanzania, payouts per group to the household are about 25 percent of average monthly consumption, while households are typically a member of about 3 groups.

In short, these sums are substantial, and given the large expenses required for socially acceptable funerals, the funeral insurance groups perform a crucial role in these communities. However, one should not forget that besides this substantial insurance, much risk remains uninsured, resulting in substantial welfare fluctuations and losses - for example, see Dercon and Krishnan (2000) and Dercon and De Weerdt (2002). Dercon and De Weerdt (2002) found that health shocks were causing households to cut back on average about 20 percent of non-food expenditure in the Tanzanian sample. In Ethiopia in 1994-95, more than 10 percent of households drifted into poverty directly related to shocks. Exploring ways to strengthen funeral societies so that they can offer more benefits to their members and the community would be worthwhile. This will be discussed in the next section.

\footnotetext{
${ }^{19}$ The fact that the poor spend relatively more on funeral expenses than health expenditures than the rich is also an indictment of the health service quality and access offered to the poor in Ethiopia. It suggests a lower income elasticity for funeral spending than for health spending, which implies that funerals are considered more of a necessity than health spending by households. When incomes fall, they will cut back more on health than on funerals: they consider it better to spend money on burying people than trying to cure them.
} 


\section{Scaling up the Funeral Associations?}

The study of these insurance groups is interesting in itself. Indeed, one key argument in this paper is that indigenous insurance groups, such as funeral societies are understudied in the literature. But a further issue takes centre stage in this section: what can be learned from these institutions for policy, and more specifically, can these groups be the basis of scaling up insurance and other developmental activities? It is often stressed that developing policies that strengthen indigenous risk-sharing arrangements should be an important part of general social protection policies (see Dercon, 2004, for a general discussion; see e.g. Preker et al., 2001 for a discussion focusing on health financing). Typically, these indigenous arrangements are usually seen as informal, reciprocal systems of mutual support and question marks exist about whether they could survive any attempt to formalize these arrangements (Conning and Kevane, 2004). However, if existing arrangements are formalized and based on well-organized groups, then the potential exists for effective scaling up. In this section, the issue of scaling up the funeral societies is assessed. First, some general arguments why they may be useful partners for interventions are presented. Then, the types of interventions that could be supported are discussed.

The general argument to target funeral societies to scale up is relatively straightforward. First, these groups are independent and well-organized. They have lists of members, written rules and regulations, well-defined contributions, regular meetings, elected executive committees. They have group property, in the form of durables and may indeed keep substantial assets from past contributions, membership fees and fines. But they still combine some of the strengths of 'informal' institutions, with members from relatively well defined communities and networks, and nested in accepted customary legal systems. These factors contribute to a more conducive 
informational and enforcement environment than typically bedevilling market based systems. They also appear to be generally inclusive organizations - with the poorer groups having access to them, and most likely more so than in more informal arrangements or in other types of institutions. They appear often to transcend gender, age, wealth, ethnicity and religion. Finally, there is also some favorable evidence of their ability to handle change, not least since their history suggests a flexible evolution to improve their organization and functioning in the context of a changing political environment.

There are two directions in which these institutions could be strengthened. First, they could be assisted in extending their activities towards broad developmental purposes, building on their ability to organize and mobilize people, and more broadly, on their existing social capital. Alternatively, they could focus on what they are doing at present: insurance provision and related financial activities.

The advantages to engage the funeral societies into broader developmental activities are substantial: their organizational strengths, independence and inclusiveness make the funeral societies excellent grassroots organizations for channelling development activities and funds. Some NGOs, most notably ACORD in Ethiopia, but also a number of indigenous NGOs in Ethiopia, are trying to build on iddirs for broad community-related development activities with some success, for example in the area of health education, water and sanitation. ${ }^{20}$

\footnotetext{
${ }^{20}$ More details are in Dercon et al. (2004). It should be noted that in Tanzania, in the survey area in Kagera Region and beyond, no evidence could be found of the engagement of local funeral groups in any other developmental activities, so the evidence presented has to be based on the Ethiopian experience.
} 
Using the iddir for broad development activities may not be without problems. There is first a legacy of past experience of interaction with 'formal' institutions, not least with government institutions. In Nyakatoke in Tanzania, the emergence of the insurance groups is closely linked with splits from government-sponsored institutions that were hijacked for political purposes. In Ethiopia, there was the clamp-down and security related registrations in the 1960s, and subsequent attempts (in the 1970s) by local and national government authorities to use the iddirs for political ends as well as the marginalization of the indigenous groups during the Derg period in the 1980s. Indeed, it is likely that these organizations will be very suspicious towards broad government-sponsored interventions targeted at the funeral associations in both countries. Furthermore, any broader role of the iddirs in developmental activities is bound to require registration and some forms of regulation - which may well be interpreted as attempts to control and interfere with their existing activities. In short, the risk of capture by political and other groups may well be real threat.

There is also an issue of inclusion. It is no doubt a strength that these institutions are relatively inclusive, both within and across communities. However, this is bound to be under threat if involving these institutions into broader developmental work would require some further formalization, regulation and registrations. Making them suitable to handle further activities will be costly and also requiring more educated staff, resulting in exclusion of some of the 'poorer' associations and groups from these activities.

Finally, there is the issue that broader developmental work would require additional skills and other changes in these institutions. In fact, it is striking that in both contexts, there is evidence that these associations initially were involved in other activities, but that now their focus seems largely 
on insurance, more specifically funeral insurance, a function they appear to have perfected. Broader activities would require changes in constitutions and bylaws, building consensus among members and obtaining relevant expertise. This would be largely uncharted territory, and involve substantial risk for these institutions, despite their inherent flexibility.

What about the other route - scaling up in the direction of insurance and finance related activities? Given that the expertise of the funeral associations is insurance and credit, it would be a strong argument to get involved in further insurance provision and broader microfinance activities. These institutions are currently expected to perform such activities - and the evidence suggests that they have perfected handling issues such as funeral insurance. In Ethiopia, they also fulfill a credit provision function, even though largely focused on credit as insurance. There are at least three possible directions, as illustrated by the activities of one particular organization, the Shashemene Microfinance Institution, an NGO in Ethiopia whose activities include working directly with iddirs, and by the evidence related to health insurance initiatives ${ }^{21}$. The options, which are not mutually exclusive, are savings facilities, credit provision and further insurance, including for health.

The fact that these associations are well-organized institutions with an insurance and even a credit objective creates possibilities for a number of microcredit and other microfinance products, for example linked to some microfinance institution (MFI). Below are some of the possibilities. First, savings facilities could be the first facility to be offered by a MFI - taking advantage of the

21 The Shashemene Iddir Microfinance institution has been active for about three years and currently works with 64 iddirs covering 2500 members in the town of Shashemene in Oromiya Region in Ethiopia. The initial loanable funds were given to them by ACORD. 
regular meetings, and the habit of giving contributions, as in the case of many of the Ethiopian funeral associations. The Shashemene Microfinance Institution used this practice.

Secondly, credit may be extended via these groups. Group-based lending is a favored intervention, not least given the example given by Grameen Bank in Bangladesh (Morduch, 1999). Besley (1993) emphasized the use of group lending, especially if these groups can exert some pressure to enforce repayment. Even without social pressure, joint liability can under certain circumstances provide the necessary incentives to sustain lending operations. Established funeral groups, with well-defined incentives to cooperate to sustain their funeral and other insurance activities, may need less social pressure to ensure repayment if the insurance operations are interlinked with credit provision and repayment. Furthermore, Conning and Kevane (2004) noted that a key problem with introducing microfinance (or in general, scaling up financial market operations in areas where formal financial markets were largely missing) is the lack of intermediary capital essentially, some agent that possesses local information and that would be willing to commit his capital so as to have a vested interested in monitoring repayment. This would allow this agent to be chosen as the 'delegated monitor', and assist in crowding in capital into the local community.

The funeral groups could be in a unique position to exploit their structure and organization to serve these different purposes. For example, consider those funeral groups that collect regular contributions. These groups could be asked to hold their reserves (effectively, its loanable funds) in a savings account with a MFI, providing collateral for any credit. In return, the MFI should match the funds, with the result that the total loanable funds become a multiple of the initially available loanable funds without MFI involvement. Contracts could then be designed to make the iddir an effective 'delegated monitor'. Via its committee (which is controlled by its members), the 
iddir could itself decide who gets the loans - as it typically would do for its own credit operations. It would be fully in charge of screening, monitoring and ensuring repayment. The iddir would be jointly responsible for repayment to the MFI, and the savings would be used as collateral, while standard joint liability conditions, such as cutting off further credit if repayment does not materialize, and punctual repayment giving access to more funds. In short, it is a form of group lending, but as a well-organized institution with financial experience, the iddir has more freedom and responsibility than usual group-based schemes, increasing its efficiency and cutting transactions costs, and joint liability could be complemented with collateral via the iddir's own reserves.

A third option is to help the funeral associations to give better and more insurance. There are a number of possibilities in this respect. First, one could arrange better (cheaper) coverage for funerals, by reducing their costs and sustainability via simple reinsurance schemes. Reinsurance of the mortality risk could have substantial benefits. Most groups using regular contributions to sustain their operations report having to contribute extra once in a while to ensure the survival of the group when there a sequence of abnormally high claims. In at least one instance, a group in Ethiopia had reportedly collapsed in the study villages. An increased size of each group would reduce the probability of this collapse, but the size of groups remains restricted due to increased incentives for groups to deviate (Genicot and Ray (2003)) and due to the deterioration of mutual information as the group is extended to include more members. However, schemes of reinsurance could be implemented, in which groups pool their risk of running out of funds to honor payouts, for example via a MFI. Pricing such contracts is not self-evident and requires substantial data. Crucial issues would include means of verification (for example via death certificates) and some form of audited accounts, but these are issues that could be overcome. The benefit would be that 
more risk pooling would be achieved, without fundamentally undermining the internal dynamics within each group. At the same time, premiums could actually be reduced, or a higher share of the reserves could be used for credit provision within each group.

Secondly, the funeral societies could also be helped to increase the cover they offer to their members. Funeral insurance is a relatively easy product - with straightforward monitoring, and the issue of moral hazard is less relevant. Mortality risk also has relatively limited covariance within communities, so that small group-based schemes may well be able to handle the risk involved. The other products offered in both countries typically focus on non-covariate risk, such as the destruction of a house or fire, limiting moral hazard, despite living in relative proximity of all the members. Covariate risks, whereby claims would be put in by many members at the same time, typically cannot be handled by these groups. When illness insurance is offered, as the hospitalization insurance offered by the women's groups in Tanzania, its design still aims to ensure proper monitoring (not all illnesses but only hospitalization is insured) while moral hazard is limited by only offering lump-sum payments irrespective of costs. In short, even in this relatively high information environment, the type of risk handled is restricted, focusing on noncovariate and relatively frequent risks. Other products may not be easily offered, unless solutions for monitoring and sustainability are found. ${ }^{22}$

There are substantial problems that would need careful attention related to the sustainability of these institutions when they are encouraged to increase the products they offer, most notably the

\footnotetext{
${ }^{22}$ Health insurance is one possible product. Some attempts are under way to encourage increased health insurance via the iddirs in Ethiopia. Mariam (2003) reports on a feasibility study for such a scheme. For a detailed discussion see Dercon et al. (2004).
} 
problem of the relatively small risk pool. Two issues will be briefly discussed. First, reducing information costs would reduce costs and make the institutions more sustainable. Better monitoring possibilities, for example via interlinked contracts, could allow risks otherwise affected by moral hazard to be more readily included. Secondly, the possibilities of reinsurance should be explored further, since by widening the risk pool, local institutional arrangements can become more sustainable. In fact, reinsurance could create possibilities to increase coverage into the direction of locally covariate risks (i.e. risks that affect a large number of people within one group, but only affecting a few groups). Examples are weather risks, but also local peaks in morbidity, such as linked to seasonal effects (malaria) or even local epidemics. However, a standard but key impediment for reinsurance to be feasible is the need for an acceptable means of verification that the events indeed took place, to be able to price reinsurance contracts. Indeed, the dismal history of crop insurance policies in many developing countries would not suggest that this route would be desirable. There would nevertheless be possibilities for combining alternative schemes. One example are the recent suggestions regarding weather insurance policies, whereby payments of insurance policies are triggered by monitored local level rainfall levels, not by reported output levels (Skees et al., 2004). Similarly, recent suggestions related to health financing focus on systems of reinsurance of community-based financing schemes, triggered by average risks, not individual risks. Given the efficiency and equity gains than can be achieved, subsidies to these schemes could be justified (Dror and Preker, 2002). ${ }^{23}$ These models could be used for other risks as well. Groups could be invited to take out these policies from an MFI or other financing institutions, but how they handle and distribute payouts among their members could be left to the local insurance group. In sum, there is substantial scope for using funeral

${ }^{23}$ A detailed discussion of all the issues surrounding reinsurance is beyond the scope of this paper, but the reader is referred to Dror and Preker (2002). 
societies to offer alternative credit and insurance products. The local experience with finance products could be a substantial advantage. Nevertheless, funeral insurance is a relatively easy product, and to keep the institution sustainable, other assistance with management, reinsurance and financing may be required to assist with the transformation of the funeral societies. As far as could be established, there is no record in Tanzania of NGOs or the state working with funeral groups, while much careful evaluative work of the limited experience in Ethiopia is required to establish the appropriate models.

\section{Conclusions and Policy Implications}

This paper has provided a discussion of local institutions largely unstudied in the development literature: indigenous voluntary associations with a focus on insurance. Some examples from Tanzania and Ethiopia can be presented. These insurance groups focus largely on funeral insurance, but also provide in a substantial number of cases hospitalization, fire and house insurance, as well as financial services such a short term credit. These groups have written membership lists and rules, with well-defined coverage and payout schedules. A significant number of them charge regular contributions resulting in significant substantial asset holdings. They are non-market institutions but also strongly independent from local political forces, and with elected committees. In each community studied, a large of number of these institutions were found, often offering similar or only slightly differentiated products, and people are members of several different institutions to increase their coverage. These institutions are rather inclusive. The evidence suggests that only limited sorting according to socio-economic background occurs, and possibly much less so than in 'informal' networks of mutual support. 
They may well be suitable institutions for many development activities. There are an increasing number of examples in Ethiopia of successful involvement in more broad development activities or more microfinance related activities, in collaboration with local NGOs. But the success of such activities should not simply be taken for granted. These institutions have developed in the way they did, partly in response to attempts by political forces to capture communities for their own purposes. A systematic attempt by government-led institutions to scale up these insurance groups may be met with deep suspicions and perceived to be a threat to their own continuation. Strictly voluntary schemes, based on extensive experimentation, are the only realistic way forward. However, in a context where ownership and community-based development are central catchphrases in policy design and implementation, offering these insurance groups possibilities to be included in these process and providing them with ways to strengthen themselves their capacities would at least be a sensible strategy.

One issue has not been discussed in detail in this paper. The current HIV/AIDS crisis may well put pressure on these institutions, risking their very survival or at least making membership more costly and beyond reach of the poor. In Pankhurst and Mariam (2004) and Dercon et al. (2004), a start is made in assessing its implications. Essentially, the HIV/AIDS crisis may require urgent interventions for funeral societies that are faced with unprecedented changes in the parameters of their activities due to increased mortality of younger cohorts. One option that should be investigated is to design a simple safety net, and iddirs could be offered the choice to opt in. It could offer subsidized reinsurance to those funeral associations with clear records of mortality in their group. Payouts from the scheme could come when mortality figures can be proven to be increasing over time. Furthermore, more systematic efforts should be made to make funeral societies agents for information on HIV/AIDS. 


\section{BIBLIOGRAPHY}

ATIM, C. (1998), Contributions of mutual health organizations to financing delivery and access to health care: synthesis of research in nine West and Central African countries. Bethesda: Abt Associates Inc.

AYALEW, DANIEL (2003), Essays on Household Consumption and Production Decisions under Uncertainty in Rural Ethiopia, Ph.D. Dissertation, Catholic University of Leuven.

BESLEY, T., (1993), 'Savings, Credit and Insurance', in J. Behrman and T.N.Srinivasan (eds.), Handbook of Development Economics, vol.III, Amsterdam: North Holland.

BOLD, T. AND S. DERCON (2004), 'Funeral Insurance Groups in Ethiopia', University of Oxford, mimeo.

BOLD, T. (2003), 'Group Formation in Informal Insurance Arrangements', Nuffield College Oxford, mimeo.

CONNING, J. AND M. KEVANE (2004), 'Why isn't there more Financial Intermediation in Developing Countries?', chapter 15 in Dercon, S. (ed.), Insurance against Poverty, Oxford University Press.

COATE, S. AND M. RAVALLION (1993), 'Reciprocity without Commitment: Characterisation and Performance of Informal Insurance Arrangements', Journal of Development Economics, Vol.40, 1-24.

DEJENE AREDO (1993), 'The informal and semiformal financial sectors in Ethiopia: A Study of the Iqqub, Iddir and Savings and Credit Co-operatives', AERC, Research Paper 21, Nairobi: African Economic Research Consortium.

DEJENE AREDO (1998), 'The Iddir Theory and Practice', paper presented at the workshop organized by Ethiopian Society of Sociologists, Social Workers and Anthropologists, Addis Ababa.

DERCON, S. (2002), 'Income Risk, Coping Strategies and Safety Nets', World Bank Research Observer, vol. 17, 141-166.

DERCON, S. (ed.), (2004), Insurance against Poverty, Oxford University Press.

DERCON, S. AND P. KRISHNAN (2003), 'Changes in poverty in villages in rural Ethiopia: 1989-95', in A.Booth and P.Mosley (eds.), The New Poverty Strategies, Palgrave MacMillan, London. 
DERCON, S. AND P. KRISHNAN (2000), 'Vulnerability, seasonality and poverty in Ethiopia', Journal of Development Studies, Vol.36, No.6, August

DERCON, S. AND J. DE WEERDT (2002), 'Risk-sharing networks and insurance against illness', Centre for the Study of African Economies, Working Paper Series 2002-17.

DERCON, S., T. BOLD, J. DE WEERDT AND A.PANKHURST (2004), 'Extending Insurance? Funeral Associations in Ethiopia and Tanzania', OECD Development Centre Working Paper, Paris.

DE WEERDT, J., (2004), 'Risk-sharing and Endogenous Group Formation', chapter 10 in Dercon, S. (ed.), Insurance against Poverty, Oxford University Press.

DE WEERDT, J., (2001), 'Community Organizations in rural Tanzania: A Case Study of the Community of Nyakatoke, Bukoba Rural District', IDS, University of Dar es Salaam and CES, University of Leuven, Belgium, The Nyakatoke Series, Report no. 3.

DROR, D.M. AND A. PREKER (2002) (eds.), Social Reinsurance. A New Approach to Sustainable Community Health Financing, Washington D.C and Geneva: The World Bank and International Labor Office.

FAFCHAMPS, M. AND S. LUND (2003), 'Risk-Sharing Networks in Rural Philippines', Journal of Development Economics, vol.71, no. 2, Pages 261-287

GENICOT, G. AND D. RAY (2003), 'Endogenous Group Formation in Risk-Sharing Arrangements", Review of Economic Studies, 70, 87-113.

GHATAK, M. (1999), 'Group Lending, Local Information and Peer Selection', Journal of Development Economics, vol. 60.

GRIMARD, F. (1997), 'Household Consumption Smoothing through Ethnic Ties: Evidence from Côte d'Ivoire', Journal of Development Economics, Vol.53, 391-422.

GUGERTY, M.K. AND M.KREMER, (2002), 'The Impact of Outside Funding on Community Organizations of the Disadvantaged', The World Bank, mimeo.

HOFF, K. (1997), 'Informal Insurance Arrangements: an Equilibrium Analysis', University of Maryland, mimeo.

JÜTTING, J. (2003), “Do Community-based Health Insurance Schemes Improve Poor People's Access to Health Care? Evidence from Rural Senegal", World Development, vol.32, no.2, pp. 273-288.

LIGON, E., J. THOMAS AND T. WORRALL (2002), 'Informal Insurance with Limited Commitment: Theory and Evidence from Village Economies', Review of Economic Studies, vol.69, no.1, 209-244. 
MARIAM, D.H. (2003) 'Indigenous social insurance as an alternative financing mechanism for health care in Ethiopia (the case of eders)', Social Science and Medicine, vol. 56, pp.17191726.

MOGUES, T. (2004), 'Shocks, Livestock Asset Dynamics and Social Capital in Ethiopia', University of Wisconsin-Madison, mimeo.

MORDUCH, J. (1995), 'Income Smoothing and Consumption Smoothing', Journal of Economic Perspectives, Vol.9 (Summer), 103-14.

MORDUCH, J. (1999), 'The Microfinance Promise', Journal of Economic Literature, vol. 37, 1569-1614.

PANKHURST, A., (2003), 'The Role and Space for Iddirs to participate in the Development of Ethiopia', in Pankhurst, A. (ed.) Iddirs: Participation and Development, Proceedings of the Ethiopian National Conference 20-21 December 2001, Addis Ababa Agency for Cooperation and Research in Development, Addis Ababa, pp.2-41.

PANKHURST, A. AND D.H. MARIAM (2004), 'The Iddir in Ethiopia: Historical Development, Social Function and Potential Role in HIV/AIDS Prevention and Control', NorthEast African Studies, forthcoming.

PREKER, A.S., G.CARRIN, D.M.DROR, M.JOAKOB, W.HSIAO AND D.ARHIN (2001), Role of Communities in Resource Mobilization and Risk Sharing, A Synthesis Report, HNP Discussion Paper, The World Bank.

PUTNAM, R.D. WITH R.LEONARDI AND R.Y.NANETTI (1993), Making democracy work: Civic traditions in modern Italy, Princeton, NJ: Princeton University Press.

RAY, D. (1998), Development Economics, Princeton: Princeton University Press.

ROTH, J. (1999), 'Informal Micro-Finance Schemes: the case of funeral insurance in South Africa', ILO, mimeo.

RUTHERFORD, S. (2001), The Poor and their Money, Delhi: Oxford University Press for India.

SHEWAMOLTOT, A. (2001), 'The socio-economic impact of HIV/AIDS on iddirs with particular reference to iddirs in Woreda 11', Senior Essay in Sociology, Addis Ababa University.

SKEES, J., P. VARANGIS, D. LARSON AND P. SIEGEL (2004) 'Can Financial Markets be Tapped to Help Poor People Cope with Weather Risks?', chapter 18 in Dercon, S. (ed.), Insurance against Poverty, Oxford University Press.

STIGLITZ, J. (1989), 'Rational Peasants, Efficient Institutions, and a Theory of Rural Organization: Methodological Remarks for Development Economics', chapter 2 in P.Bardhan, The Economic Theory of Agrarian Institutions, Oxford University Press. 
TESFAYE, S. (2002), 'The role of civil society organizations in poverty alleviation, sustainable development and change: the cases of iddirs in Addis Ababa, Akaki and Nazreth', MA Thesis in Social Anthropology, School of Graduate Studies, Addis Ababa University.

TOWNSEND, R.M. (1994), 'Risk and Insurance in Village India', Econometrica, Vol.62, No.3, 539-91.

TOWNSEND, R.M. (1995), 'Consumption Insurance: An Evaluation of Risk-Bearing Systems in Low-Income Economies', Journal of Economic Perspectives, Vol.9 (Summer), 83-102. 